\title{
Contemporary results of balloon valvuloplasty and surgical valvotomy for congenital aortic stenosis
}

\author{
Michael A Gatzoulis, Michael L Rigby, Elliot A Shinebourne, Andrew N Redington
}

\begin{abstract}
The purpose of this study was to compare contemporary results of balloon dilatation and surgery for valvar aortic stenosis in infants and children in the five years between August 1988 and October 1993.

Thirty four children underwent attempted balloon valvuloplasty (age 1 day-16 years, weight $1720 \mathrm{~g}-68 \mathrm{~kg}$ ) (group 1), eight of whom were neonates with critical aortic stenosis. During the same period, 17 children underwent direct surgical valvotomy (group 2) (seven neonates).

Successful balloon valvuloplasty was achieved in $33(97 \%)$ with immediate reduction in the instantaneous systolic pressure gradient from 82 to $34 \mathrm{~mm} \mathrm{Hg}$ (mean). There were two deaths in this group (both neonates), the second in a preterm neonate from necrotising enterocolitis. Complications requiring intervention in group 1 were aortic
\end{abstract}

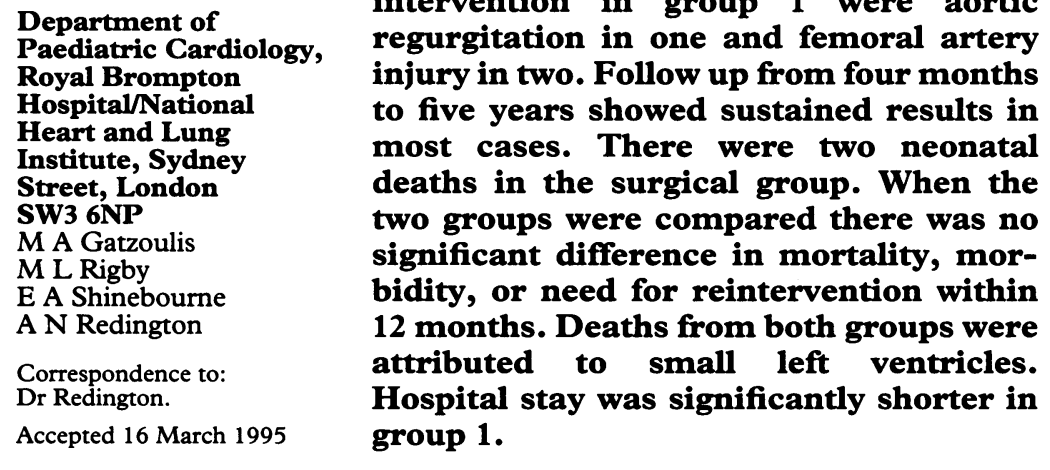

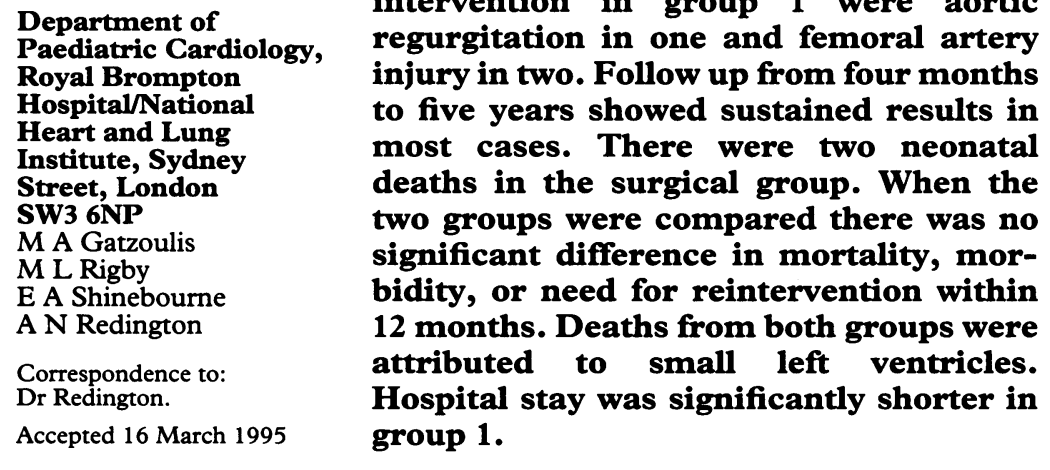

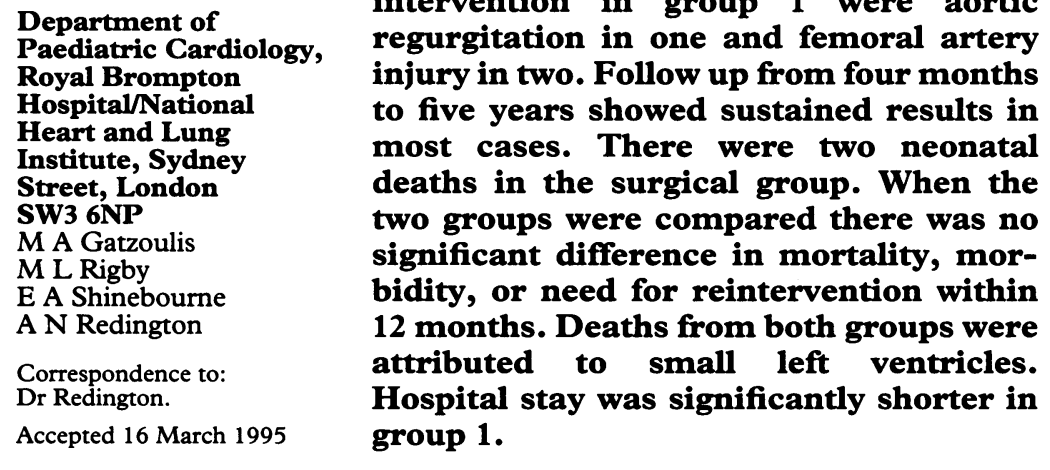

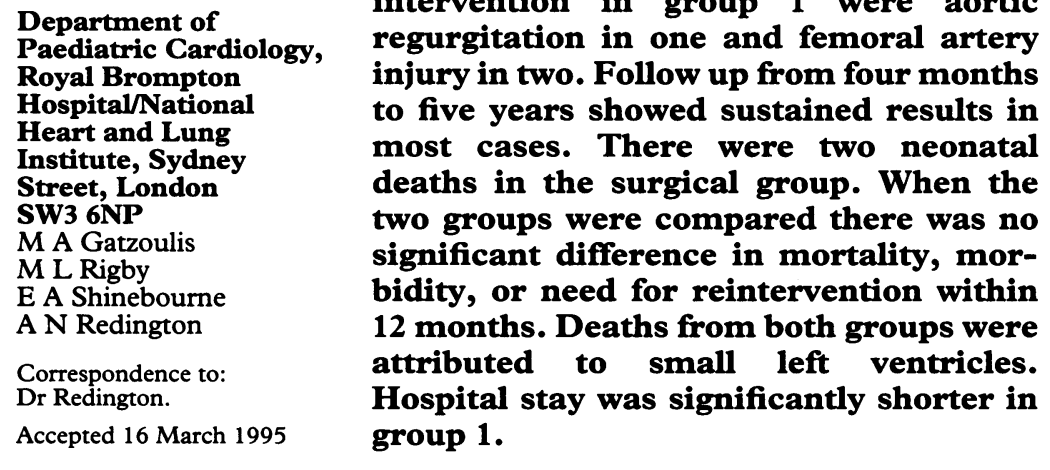

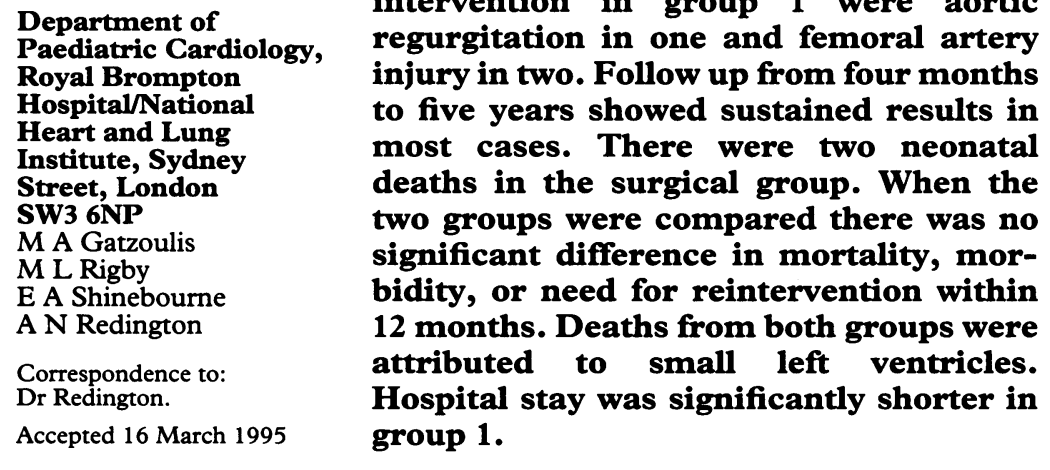

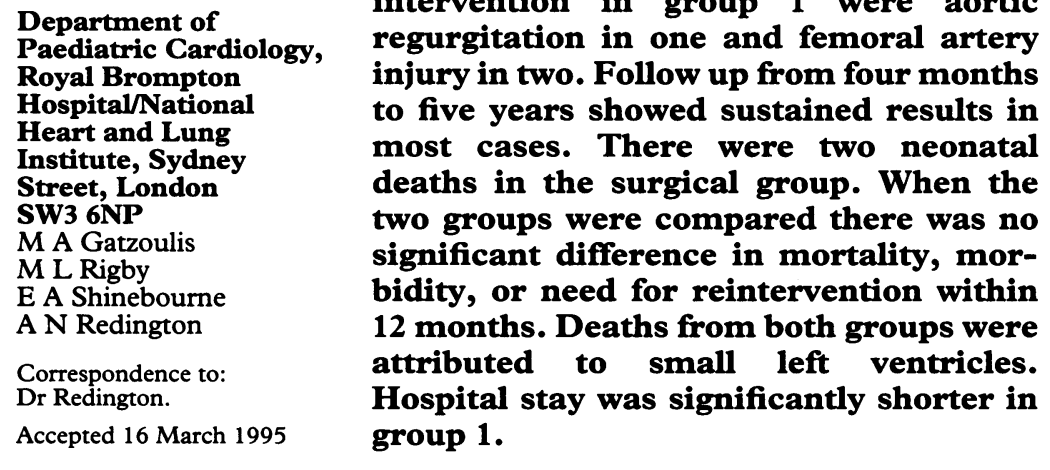

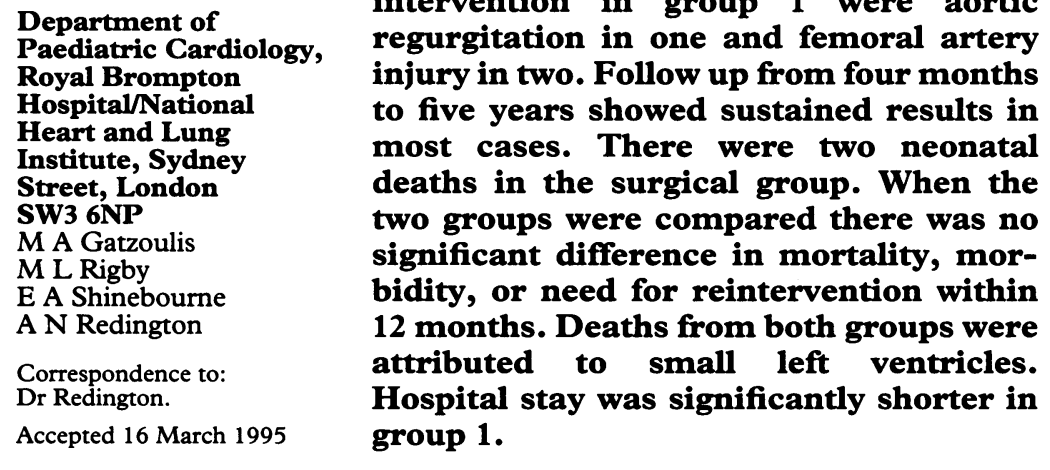

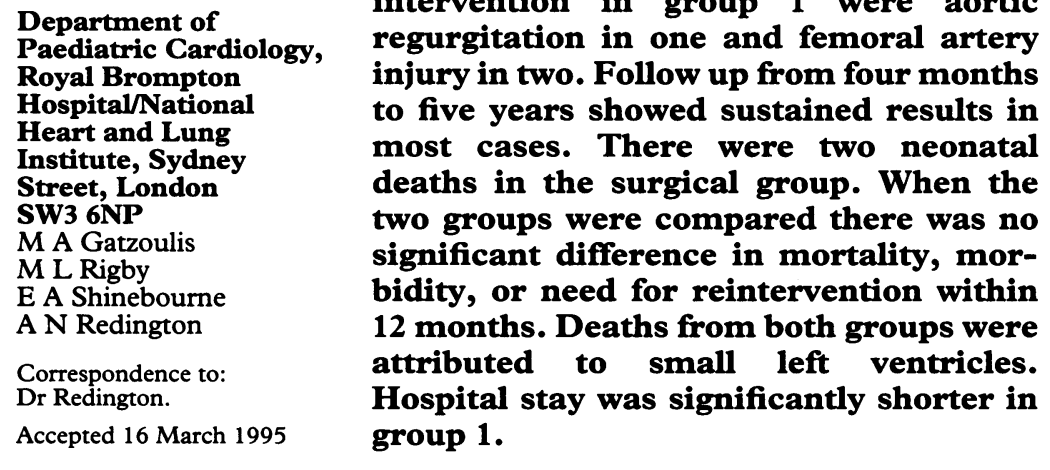

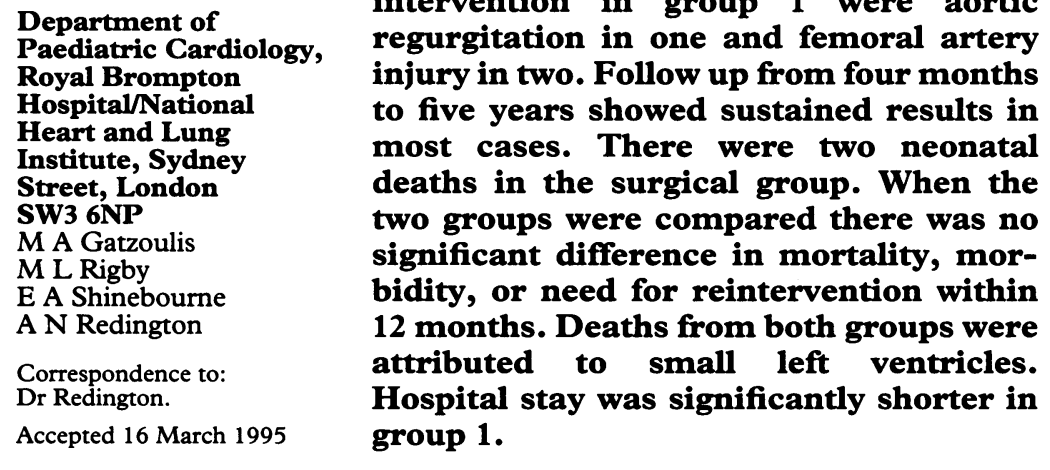

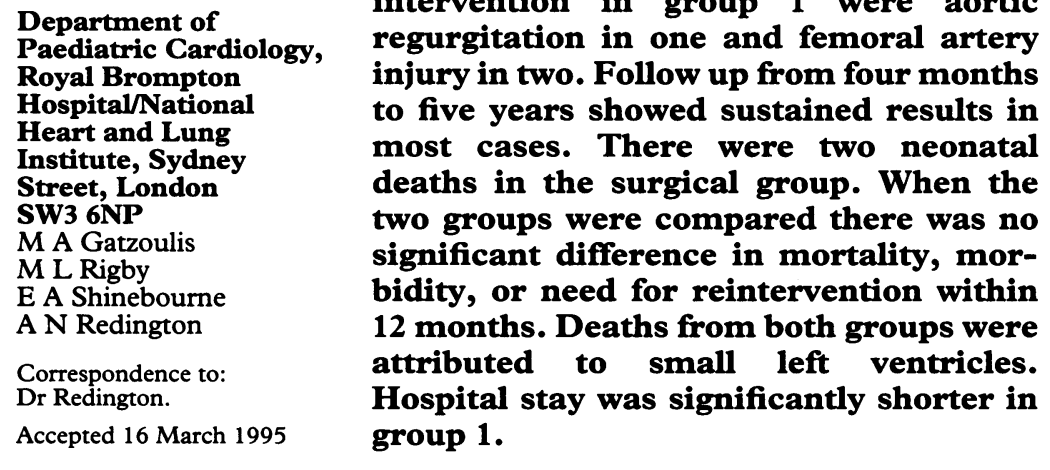

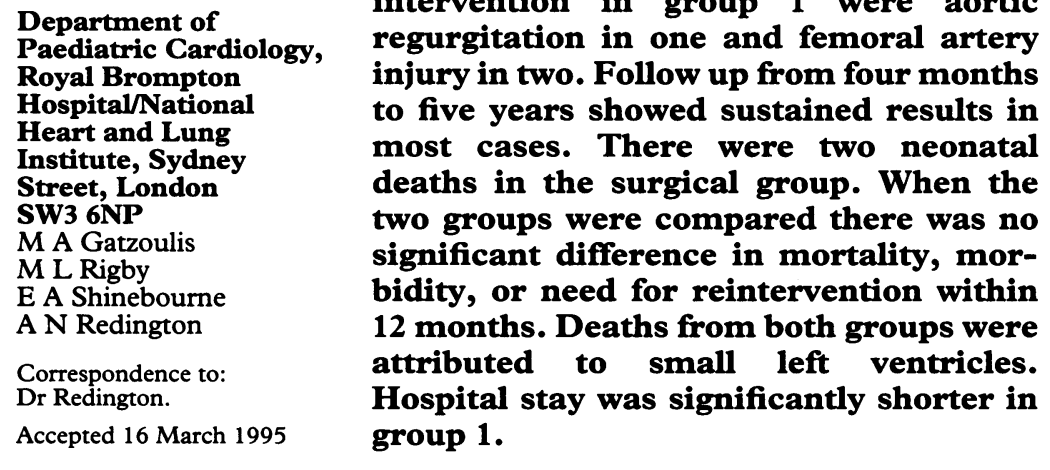

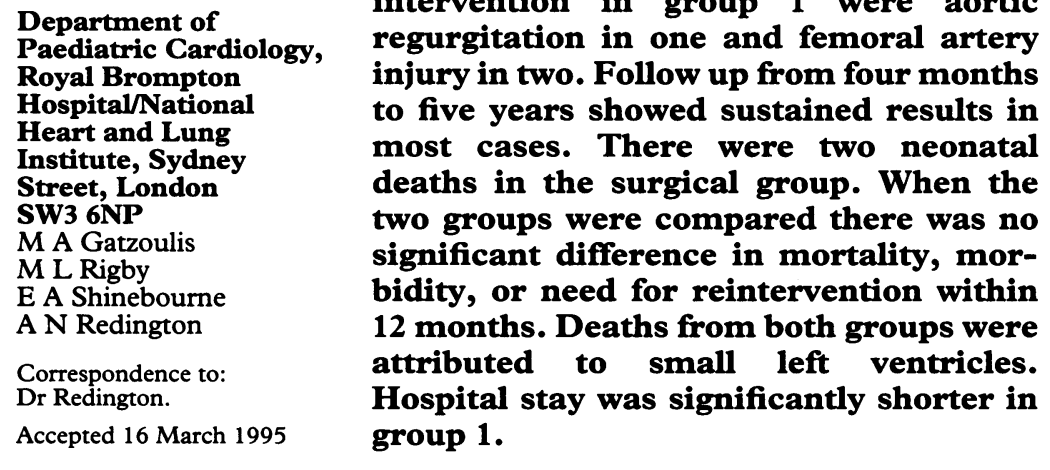

Table 1 Clinical, anatomic, and haemodynamic characteristics

\begin{tabular}{|c|c|c|c|}
\hline & Balloon valvuloplasty & Surgical valvotomy & Significance \\
\hline \multicolumn{4}{|l|}{ Age at procedure } \\
\hline Whole group (months) & $(n=34)$ & $(n=17)$ & \\
\hline $\begin{array}{l}\text { Range } \\
\text { Median }\end{array}$ & $\begin{array}{l}0 \cdot 03-190 \\
5\end{array}$ & $\begin{array}{l}0 \cdot 03-180 \\
3\end{array}$ & \\
\hline Neonates (days) & $(n=8)$ & $(n=7)$ & \\
\hline Range & $1-26$ & $1-28$ & \\
\hline \multicolumn{4}{|l|}{$\begin{array}{l}\text { Median } \\
\text { Weight (g) }\end{array}$} \\
\hline Neonates & $(n=8)$ & $(n=7)$ & \\
\hline Range & $1720-5000$ & $2900-4000$ & \\
\hline Median & 3500 & 3000 & \\
\hline \multicolumn{4}{|l|}{ Prostaglandin infusion } \\
\hline \multicolumn{4}{|l|}{$\begin{array}{l}\text { Neonates } \\
\text { AV/unicommissural }\end{array}$} \\
\hline \multirow{2}{*}{\multicolumn{2}{|c|}{$\begin{array}{l}\text { Whole group } \\
\text { AV/bicuspid }\end{array}$}} & $2 / 17$ & \\
\hline & & & \\
\hline \multicolumn{4}{|l|}{$\begin{array}{l}\text { Whole group } \\
\text { Peak AV gradient/before* }\end{array}$} \\
\hline \multirow{2}{*}{\multicolumn{4}{|c|}{$\begin{array}{l}\text { Whole group } \\
\text { Peak AV gradient/after }\end{array}$}} \\
\hline & $(n=33)$ & $(n=17)$ & \\
\hline \multirow{2}{*}{\multicolumn{4}{|c|}{$\begin{array}{l}\text { Whole group } \\
\text { AV gradient reduction/after* }\end{array}$}} \\
\hline & $(n=7)$ & $(n=7)$ & \\
\hline \multicolumn{4}{|l|}{$\begin{array}{l}\text { Neonates } \\
\text { V gradient reduction/after* }\end{array}$} \\
\hline $\begin{array}{l}\text { AV gradient reduction/after } \\
>1 \text { month }\end{array}$ & $\begin{array}{l}(n=26) \\
48.9(19.4)\end{array}$ & $\begin{array}{l}(n=10) \\
40 \cdot 4(12 \cdot 4)\end{array}$ & NS \\
\hline & & & \\
\hline
\end{tabular}

NS: not significant

Peak aortic valve (AV) gradient: transaortic peak instantaneous systolic pressure gradient on Doppler before and after the procedure.

${ }^{\star}$ Mean (SD) measured in $\mathrm{mm} \mathrm{Hg}$.
It is concluded that balloon dilatation for valvar aortic stenosis is effective and safe for the entire paediatric population. The results compare favourably with those of surgery.

(Arch Dis Child 1995; 73: 66-69)

Keywords: heart defects, congenital, aortic valve stenosis, balloon dilatation.

Aortic valve stenosis accounts for 3-6\% of congenital heart disease. ${ }^{12}$ Percutaneous balloon valvuloplasty, first described in $1984,{ }^{3}$ is now well accepted as a form of treatment for valvar aortic stenosis beyond the neonatal period. ${ }^{45}$ For critical aortic stenosis though, the role of balloon valvuloplasty still remains controversial. Zeevi and colleagues reported favourable results of balloon valvuloplasty for valvar aortic stenosis when compared with those of surgery in the preceding era. ${ }^{6}$ This paper attempts to compare the contemporary results of both surgical and balloon valvotomy in children with valvar aortic stenosis over the last five years.

\section{Patients and methods}

All children who underwent aortic valve surgery or balloon dilatation between August 1988 and October 1993 in our institution form the study's population. Only patients with valvar aortic stenosis were considered, as severe associated abnormalities (that is, severe mitral valve involvement) can influence the outcome. ${ }^{7}$ Patients who at presentation were thought to be unsuitable for biventricular repair were also excluded. Data for analysis were obtained from the medical, echocardiographic, catheterisation, surgical, and necropsy records.

GROUP 1: BALLOON VALVULOPLASTY

Thirty four children with valvar aortic stenosis underwent balloon dilatation during this five year period (age and weight are presented in table 1). Eight were neonates in severe congestive heart failure at presentation, with four receiving prostaglandin infusion to maintain ductal patency. Associated lesions or additional pathology was present in 12 (table 2). The anatomy of the aortic valve, as determined echocardiographically or at subsequent surgery or necropsy, was unicommissural in three, bicuspid in 15, and 'tricuspid' with a limited commissural fusion in the remainder. Three children had had a previous surgical valvotomy and one a balloon valvuloplasty before 1988 . 
Table 2 Associated lesions and/or pathology

\begin{tabular}{lll}
\hline & $\begin{array}{l}\text { Balloon } \\
\text { valvuloplasty }\end{array}$ & $\begin{array}{l}\text { Surgical } \\
\text { valvotomy }\end{array}$ \\
\hline Patent arterial duct & 6 & 5 \\
Ventricular septal defect (small) & 4 & 1 \\
Atrial septal defect (secundum) & 1 & 1 \\
Pulmonary stenosis (mild) & 1 & - \\
Intrauterine growth retardation & 2 & - \\
Hyaline membrane disease/ & 2 & 1 \\
prematurity & - & 1 \\
Infant of diabetic mother & - & 1 \\
CHARGE association & &
\end{tabular}

Balloon dilatation technique

Balloon dilatation was performed through the femoral artery under general anaesthesia. The umbilical arterial approach was used in one case. An aortogram was first performed and the diameter of the aortic valve was measured at its hinge point with the aortic sinuses and the balloon size was selected so that it did not exceed this or the echocardiographic measurement. The aortic valve was crossed with a soft tip angioplastic wire, looped in a stable position within the left ventricle, and the antegrade gradient was measured. Then the balloon catheter was passed in a direct percutaneous fashion over the guide wire and positioned across the aortic valve. The balloon was inflated one to four times so that any 'waist' was abolished. Finally the withdrawal transaortic gradient was measured and a repeat aortogram was performed to assess any degree of aortic regurgitation. In eight children a balloon catheter of submaximal diameter was used initially to predilate a severely stenotic valve and permit subsequent passage of a larger balloon.

GROUP 2: SURGICAL VALVOTOMY

Seventeen children underwent aortic valve surgery during the same period, two of whom had had a previous balloon procedure during the first few months of life (table 1). Seven were neonates of whom four were transferred to our unit on prostaglandin. Additional abnormalities were seen in six (table 2). Two had an unicommissural and eight a bicuspid aortic valve. The remaining seven had a partial commissural fusion with a 'trileaflet' valve. All children underwent open aortic valvotomy, using conventional cardiopulmonary bypass with moderate hypothermia in 10 and inflow occlusion in the remainder.

There were also five children who had aortic valve or aortic root replacement during the same five year period, in three after previous surgery, in one after balloon dilatation, and in the fifth after bacterial endocarditis (table 3).

\section{STATISTICAL ANALYSIS}

Measured and calculated data are expressed as mean (SD). Comparison of the two groups was performed using the Student's $t$ test. A p value of less than 0.05 was considered significant.

\section{Results}

No significant differences were found between the clinical, haemodynamic, and anatomic characteristics (table 1) of the balloon and surgical valvotomy groups. Success was concluded primarily on clinical improvement, as reduction of the transaortic valve gradient alone could be misleading in neonatal cases with severe ventricular dysfunction. Under these circumstances a rise in the gradient may be a reflection of improved cardiac output, which exposes the stenosis, rather than a result of a failed procedure.

\section{GROUP 1}

Successful balloon valvuloplasty was achieved in 33 of $34(97 \%)$ children (including neonates) with clinical improvement in all and immediate reduction in the instantaneous peak systolic pressure gradient from $81.6(23.2)$ to $33.8(18.0) \mathrm{mm} \mathrm{Hg}$. The balloon size used ranged from 80 to $100 \%$ of the aortic valve size (mean $94(1.07) \%$ ). Screening time ranged from 11 to 42.6 minutes (mean $20.7(10 \cdot 6)$ ). The single failure was the case of a 1 day old neonate (weight $3400 \mathrm{~g}$ ) who underwent surgery after failed balloon procedure. We were unable to cross the aortic valve (the only case) and the patient was referred for surgery in poor condition bleeding from the femoral site. Death occurred soon after surgery from poor cardiac output. Postmortem examination showed a small left ventricle. The second death

Table 3 Aortic valve or root replacement

\begin{tabular}{|c|c|c|c|c|c|}
\hline & \multicolumn{5}{|l|}{ Patient No } \\
\hline & 1 & 2 & 3 & 4 & 5 \\
\hline \multicolumn{6}{|l|}{ First procedure } \\
\hline Age & & $28 \mathrm{~d}$ & $3 \mathrm{~d}$ & & $9 \mathrm{~m}$ \\
\hline Type & $\begin{array}{l}\text { Balloon } \\
\text { valvuloplasty }\end{array}$ & $\begin{array}{l}\text { Balloon } \\
\text { valvuloplasty }\end{array}$ & $\begin{array}{l}\text { Surgical } \\
\text { valvotomy }\end{array}$ & $\begin{array}{l}\text { Surgical } \\
\text { valvotomy }\end{array}$ & $\begin{array}{l}\text { Surgical } \\
\text { valvotomy }\end{array}$ \\
\hline \multirow{3}{*}{$\begin{array}{l}\text { Repeat procedures } \\
\text { Age } \\
\text { Type }\end{array}$} & Monocuspid & Monocuspid & Bicuspid & Monocuspid & Bicuspid \\
\hline & - & - & - & - & \\
\hline & - & - & - & - & $\begin{array}{l}\text { Balloon } \\
\text { valvuloplasty }\end{array}$ \\
\hline \multicolumn{6}{|l|}{ Replacement treatment } \\
\hline Age & $2 \mathrm{~m}$ & $3 \mathrm{~m}$ & $2 y$ & $3 y$ & $12 \mathrm{y}$ \\
\hline Reason & SBE & Al/LVd & $\mathrm{A} \mathbf{I}$ & & AI/AS \\
\hline Type/size in mm & $\mathrm{RH} / 14$ & $\mathrm{RH} / 14$ & $\mathrm{RH} / 16$ & RH/17 & SJP/19 \\
\hline Follow up & $16 \mathrm{~m}$, well & $6 \mathrm{~m}$, well & $\begin{array}{l}1 \mathrm{~d} / \text { died, from ventricular } \\
\text { tachycardia }\end{array}$ & & $2 \mathrm{y}$, well \\
\hline
\end{tabular}

d: days. m: months, y: years.

SBE: subacute bacterial endocarditis, AI: aortic incompetence, LVd: left ventricular dysfunction, AS: aortic stenosis, RH: root homograft, SJP: St Jude prosthesis.

$\star$ Patient referred from overseas/no follow up data available. 
was due to necrotising enterocolitis in a preterm infant (32 weeks' gestation, weight $2400 \mathrm{~g}$ ) with hyaline membrane disease and critical aortic stenosis who underwent successful balloon valvuloplasty on day 2 of life and was transferred back to the referral hospital where he died on day 8 .

\section{GROUP 2}

Fifteen $(88 \%)$ of the 17 children who underwent open valvotomy had a successful outcome with a reduction in the transaortic peak systolic pressure gradient from $69 \cdot 7(17 \cdot 9)$ to $32.9(13.0) \mathrm{mm} \mathrm{Hg}$. The two deaths were both in neonates with critical aortic stenosis who died three and eight days after surgery because of low cardiac output, which was complicated by septicaemia in the second. Necropsy showed small left ventricles in both with endocardial fibroelastosis in the first.

Hospital stay ranged from six to 19 days (mean 9.8 (3.4) days) and was significantly longer when compared with group 1 (range 2-14 days, mean $3.0(2 \cdot 6), \mathrm{p}<0.0001)$.

\section{COMPLICATIONS}

Severe aortic incompetence complicated a single case, that of a neonate with critical aortic stenosis who underwent balloon valvuloplasty at four weeks of age (table 3, patient 2). Severe femoral arterial injury necessitating intervention occurred in two patients. The first (4 days old) underwent plastic surgery/reconstruction and the second (11 years old) balloon dilatation of the vessel, both with good, sustained results. Finally there was a single case of a 12 year old girl who developed transient ischaemic electrocardiographic changes (with minimal apical dyskinesia) after successful balloon dilatation of her aortic valve, during which the $18 \mathrm{~mm}$ balloon burst. One year later she had a normal electrocardiogram, a small apical echodense region on echocardiography, suggesting fibrosis, and a normal exercise test.

One neonate from group 2 developed necrotising enterocolitis which was treated conservatively.

\section{FOLLOW UP}

\section{Group 1}

Follow up ranged from six months to four years (mean 1.4 (1.2)). All 32 live patients are well. Six patients $(17 \cdot 6 \%)$ have moderate aortic regurgitation (clinically and on Doppler) which is well tolerated. Four patients have significant residual aortic stenosis $(>60 \mathrm{~mm}$ $\mathrm{Hg}$ ), two of whom have already undergone successful repeat balloon valvuloplasty. Two additional patients were referred for surgery, one with severe aortic incompetence see above (table 3 ) and the second with residual severe stenosis six months after initial balloon valvuloplasty for critical aortic stenosis. The latter had an unicommissural aortic valve and was expected to have a better result from elective surgery.
Group 2

In the surgical group follow up ranged from eight months to five years (mean $2.45(1.55)$ ). The 15 live patients are well. One patient has moderate aortic regurgitation. Two patients had balloon valvuloplasty for significant residual aortic stenosis six months to a year after successful surgery and a third underwent aortic root replacement two years after surgery for severe mixed aortic valve disease.

\section{Discussion}

This is a retrospective study of all infants and children who underwent aortic valvotomy during a five year period (1988-93). Patients were referred either for surgery or for balloon valvotomy in a random manner which was dependent on the preference or bias of the attending physician and not on any other factors. Our study attempted to compare for the first time contemporary results of both procedures within a single centre. Despite the caveats of a retrospective non-randomised study, our two groups are comparable in their clinical and anatomical characteristics. We decided to include in the study only patients with 'isolated' aortic valve stenosis in order to eliminate other factors that might influence the outcome. ${ }^{7}$ Successful balloon valvuloplasty was achieved in all but one of our cases with no deaths directly attributable to the procedure. This represents an improvement on earlier experiences, ${ }^{89}$ and seems to reflect the advances in the design of guide wires and balloon catheters currently available for paediatric use. It is possible in the current era of antenatal diagnosis of congenital heart disease, that the outcome of infants with critical aortic stenosis could improve further as their condition at presentation can be optimised by maintaining ductal patency.

Not surprisingly, most of the deaths occurred in patients with left ventricular hypoplasia. In a study from Guy's Hospital neonatal balloon dilatation carried a $100 \%$ mortality attributed to left ventricular hypoplasia. ${ }^{10}$ Despite trying to exclude neonates, unsuitable for a biventricular repair, there are borderline cases which manifest themselves as being unsuitable by failing after either balloon or surgical valvotomy. Univentricular repair has such a poor prognosis in this group that the risk/benefit ratio for the group as a whole would support continued attempts even in borderline cases. The single case of severe aortic regurgitation after balloon dilatation was attributed to a rather dysplastic and myxomatous valve. One could argue that surgical valvotomy could have yielded a better result in this case with extreme valvar dysplasia, although the latter may be difficult to recognise by echocardiography. Other complications from the first group (femoral artery injury) were easily corrected or (mild aortic regurgitation) well tolerated. Radiation was not a particular concern as fluoroscopy time was kept short. The need for a repeat procedure, which is neither unexpected nor unacceptable, was also not different in the two groups. Repeat 
balloon dilatation is likely to carry considerably fewer risks than repeat surgery, particularly when there is myocardial dysfunction. There have been no problems with arterial access in this respect.

For older children, our results of balloon valvuloplasty confirm previous reports. ${ }^{5}$ Natural history data ${ }^{111}$ would probably justify balloon dilatation in this age group before aortic stenosis is severe in order to diminish the rate of progression of left ventricular outflow tract obstruction and left ventricular hypertrophy.

We consider both balloon and surgical valvotomy palliative forms of treatment, as the majority of these patients are likely to require aortic valve replacement later on in life. ${ }^{12}$ Balloon dilatation offers the additional attraction of deferring the definitive surgery and preserving the surgical field. Finally hospital stay is significantly shorter in the balloon dilatation group, with obvious financial benefits.

Our data suggest that balloon valvuloplasty for valvar aortic stenosis is effective and safe in neonates and older children. The results compare favourably with those of surgery. The outcome is mainly determined by the anatomy rather than the type of the procedure. As a result of this study, balloon valvuloplasty for congenital aortic stenosis has become the treatment of choice in our institution for both neonates and older children, with the possible exception of extreme valvar dysplasia sometimes seen in unicuspid and rather myxomatous aortic valves.

\section{LIMITATIONS OF THE STUDY}

The main limitation of this retrospective study was to define the selection criteria used for one or the other procedure. Given the excellent surgical results reported from our institution on valvar aortic stenosis in infancy, ${ }^{13}$ not all physicians in charge were keen in employing balloon valvuloplasty from the outset of the study period, that being a newer method. This of course, is always the dilemma with innovative techniques be they surgical or medical. Increasing experience gained in the meantime from transcatheter balloon procedures for pulmonary stenosis ${ }^{14}$ and coarctation of the aorta ${ }^{15}$ lead some of us to employ the newer technique for the management of valvar aortic stenosis in children, including neonates. As the preliminary results were not disappointing more cases were referred for the non-surgical approach. This is indeed what happened and although there was at some stage a preference or bias of the attending physician for one or other procedure, within this five year period of the study we have serendipitously two groups, which are reasonably comparable.

We would like to thank Professor Sir M Yacoub, Mr C Lincoln, and Mr D F Shore for allowing us to report their patients.

1 Kitchiner DJ, Jackson M, Walsh K, Peart I, Arnold R. Incidence and prognosis of congenital aortic valve stenosi in Liverpool (1960-1990). Br Heart f 1993; 69: 71-9.

2 Friedman WF, Benson LN. Aortic stenosis. In: Adams FH, Emmanouilides GC, eds. Moss' heart disease in infants, children and adolescents. 3rd Ed. Baltimore: Williams and Wilkins, 1983: 171

3 Lababidi Z, Jiunn-Ren WU, Walls JT. Percutaneous balloon aortic valvuloplasty: results in 23 patients. $A m \mathcal{F}$ Cardiol 1984; 53: 194-7.

4 Choy M, Beekman RH, Rocchini AP, et al. Percutaneous balloon valvuloplasty for valvar aortic stenosis in infants and children. Am $\mathcal{Y}$ Cardiol 1987; 59: 1010-3.

5 Rocchinni AP, Beekman RH, Ben Shachar G, et al. Balloon aortic valvuloplasty: results of the valvuloplasty and angioplasty of congenital anomalies registry. Am $\mathcal{F}$ Cardiol 1990; 65: 784-9.

6 Zeevi B, Keane JF, Castaneda AR, Perry SB, Lock JE. Neonatal critical valvar aortic stenosis: a comparison of surgical and balloon dilation therapy. Circulation 1989; surgical and

7 Rhodes LA, Colan SD, Perry SB, Jonas RA, Sanders SP. Predictors of survival in neonates with critical aortic stenosis. Circulation 1991; 84: 2325-35.

8 Wren C, Sullivan I, Bull C, Deanfield J. Percutaneous balloon dilatation of aortic valve stenosis in neonates and infants. Br Heart $\mathcal{F}$ 1987; 58: 608-12.

9 Kasten-Sportes CH, Piechaud JF, Sidi D, Kachaner J. Percutaneous balloon valvuloplasty in neonates with critical aortic stenosis. F Am Coll Cardiol 1989; 13: 1101-5.

10 Ladusans EJ, Parsons JM, Qureshi SA, Baker EJ, Tynan MJ. Results of percutaneous balloon dilatation for critical aortic stenosis in neonates with severe endocardial fibroelastosis (abstract). Br Heart $\mathcal{F}$ 1989; 61: 470 .

11 Hossack KF, Neutze JM, Lowe JB, Barratt-Boyes BG. Congenital valvar aortic stenosis. Natural history and assessment for operation. Br Heart $\mathcal{f} 1980$; 43: 561-73.

12 DeBoer DA, Robbins RC, Maron BJ, McIntosh CL, Clark RE. Late results of aortic valvotomy for congenital valva aortic stenosis. Ann Thorac Surg 1990; 50: 69-73.

13 Burch M, Redington AN, Carvalho JS, et al. Open valvotomy for critical aortic stenosis in infancy. Br Heart $\mathcal{f}$ 1990; 63: 37-40.

14 Rocchini AP, Kvesilis DA, Crowley D, Dick M, Rosenthal A. Percutaneous valvuloplasty for treatment of pulmonary valve stenosis in children. $\mathcal{F}$ Am Coll Cardiol 1984; 3: 1005-12.

15 Redington AN, Booth P, Shore D, Rigby ML. Primary balloon dilatation of coarctation of the aorta in neonates. Br Heart f 1990; 64: 277-81. 